\title{
APUNTES PARA UNA REVISIÓN DEL RECINTO AMU- RALLADO MEDIEVAL DE RUEDA DEL ALMIRANTE (GRADEFES, LEÓN)
}

\section{NOTES FOR A REVIEW OF THE MEDIEVAL WALLED ENCLO- SURE OF RUEDA DEL ALMIRANTE (GRADEFES, LEÓN)}

\author{
Julio Manuel Vidal Encinas \\ Junta de Castilla y León. Servicio Territorial de Cultura de León \\ videncju@jcyl.es
}

Recibido: $15 / 11 / 2015$

Aceptado: 28/12/2015

"Veinte casas miserables han quedado en lo que fué villa y cabeza de territorio; pues su fortaleza de sitio, que le valió tales honores, vuélvese hoy en daño propio, mientras crecen a su pie las aldeas de la ribera del Esla, sometidas antes bajo el poderío de su amurallado recinto" (M. GÓMEZ MORENO, Catálogo Monumental de España. Provincia de León: (19061908). Madrid. Ministerio de Instrucción Pública y Bellas Artes, p. 433).

RESUMEN: El recinto de Rueda tiene 2,8 Ha, contrariamente a las dimensiones de 0,84 y 1,7 Ha que se habían propuesto hasta el momento, en un circuito que se extiende a lo largo de $805 \mathrm{~m}$, incluyendo los muros del castillo. Conserva visible más del $60 \%$ de su trazado (509 $\mathrm{m}$ ). De ellos, más de $300 \mathrm{~m}$ del borde oriental están fuera del actual caserío. Este lienzo, dotado de torrecillas macizas como seguramente todo el recinto, se adelantó en el cerro a media ladera por razones poliorcéticas, para poder controlar la base del mismo. Además, el perímetro estuvo rodeado de foso en sus lados septentrional, oriental y occidental, parcialmente conservado.

PALABRAS CLAVE: Rueda del Almirante, muralla medieval, arquitectura fortificada medieval, fortificaciones de frontera, Castilla y León.

ABSTRACT: The paper established and updates the setting of the medieval walled town of Rueda del Almirante, which reached 2.8 hectares, instead of 0.8 and 1.7 Ha that had been proposed before. The city walled enclosure stretches along $805 \mathrm{~m}$, including the castle walls. It remains visible for more than $60 \%(509 \mathrm{~m})$. The eastern wall was outside of the village, placed in the slopes of the hillside by poliorcetic requirements. The walls was endowed with massive little turrets and surrounded by ditches partially preserved on its northern, eastern and western sides.

KEYWORDS: Rueda del Almirante, medieval walled enclosure, medieval fortified architecture, border fortifications, Castilla y León. 


\section{INTRODUCCIÓN.}

El río Esla, después de más de $50 \mathrm{Km}$ de recorrido por la Cordillera Cantábrica, se abre a la Meseta Norte a la altura de Cistierna, abandonando los viejos macizos de calizas, areniscas y pizarras, por los conglomerados, arenas y arcillas del Terciario. En su periplo más montañoso está jalonado por varios indicios de fortificaciones medievales, enormemente enriscadas y muy poco conocidas, incluso en su real localización y restos materiales visibles. De hecho, son prácticamente inexistentes sus testimonios gráficos o fotográficos, incluso en trabajos de documentación o catalogación como es la propia Carta Arqueológica de la provincia, pero también en otros de investigación, alguno, hasta el momento, el único que los ha abordado ${ }^{1}$. Heterogéneas en su configuración y emplazamiento, ello debe estar apuntando funciones y cronología también diversas. Seguramente muchas haya que tenerlas en el grupo de las más antiguas, altomedievales, pero creemos que cabe la posibilidad, como hipótesis, que alguna de ellas, levantada en muros de piedra en seco, pueda no pertenecer a estos tiempos, y ser más antiguas, quizás protohistóricas².

Cuando el Esla discurre por los friables materiales del Terciario, en plena Cuenca del Duero, su cauce se va a ampliar considerablemente, tallando en ambas riberas, pero especialmente en la de su margen derecha, importantes escarpes, con un desnivel de más de $50 \mathrm{~m}$ con relación al cauce del río. Ello hace que este emplazamiento, en el borde del páramo, permita dominar ampliamente, desde el punto de vista visual, un dilatadísimo territorio del propio valle fluvial. Es en tal contexto geográfico que se encuentra Rueda del Almirante.

\footnotetext{
${ }^{1}$ Nos estamos refiriendo al catálogo de J. A. GUTIÉRREZ GONZALEZ (1995). Fortificaciones y feudalismo en el origen y formación del Reino Leonés (siglos IX-XIII). Universidad de Valladolid, que recoge la Tesis Doctoral del autor, al igual que las fichas correspondientes de la primera edición (1987-1988) de la Carta Arqueológica de la provincia de León, de cuyo equipo formó parte.

${ }^{2}$ Es el caso, por ejemplo, de 'La Torre', un pequeño recinto amurallado en piedra en seco, asentado en el denominado 'Cerro Murrial', al norte de la localidad de Cistierna, y algunas, de la misma fábrica, situadas en las inmediaciones del castillo de Aguilar, en Sabero, que, aunque descritas como medievales (vid.: S. SANZ y T. CEMBRERO (2011). "El complejo defensivo de Aguilar". Revista Comarcal Montaña de Riaño, 37 y S. SANZ (2014). "Breve estudio del castillo de Cistierna en el cabezo del Murrial, parte integrante del complejo defensivo de Aguilar frente al Islam y Castilla, con una breve disquisición acerca del origen de la villa". Revista Comarcal Montaña de Riaño, 49), es posible que pudieran ser anteriores, protohistóricas. En cualquier caso, solo trabajos más profundos, de excavación arqueológica, podrán llegar a determinarlo de forma fehaciente. Alguno de estos sitios los hemos tratado en un reciente trabajo de documentación: J. M. VIDAL ENCINAS (2015). "Los castros arriscados en la provincia de León: un grupo castreño singular". I Jornadas Internacionales "Evolución de los espacios urbanos y sus territorios en el Noroeste de la Península Ibérica” (31 enero 2014). Facultad de Filosofía y Letras, Universidad de León. R. MARTÍNEZ PEÑÍN, y G. CAVERO DOMÍNGUEZ, (eds.), pp. 339-401.
} 
El Esla va a constituir, junto con el Cea, que corre al este, a una distancia comprendida entre $10 \mathrm{Km}$ al norte de Almanza y más de 40 a la altura de Ardón, una importante línea de demarcación o defensa en las disputas territoriales que acaecieron, a lo largo de unos 70 años, entre los reinos de León y Castilla, en unos tiempos situados a caballo de los siglos XII y XIII. En ambas fronteras, en consecuencia, se van a producir por iniciativa real diferentes decisiones que, además del factor humano de la repoblación, tendrán como objetivo fortalecerlas en tal contexto bélico ${ }^{3}$ (Fig. 1).

De acuerdo con la interpretación más generalizada del origen del castillo y recinto amurallado de Rueda del Almirante, en su formalización como fortificación de 'cal y canto', habría sido obra de Alfonso IX hacia 11954, el último monarca leonés, lo que se habría producido dentro de dos de los aspectos que más caracterizarían su reinado. Por un lado, la “... consecución de una plataforma territorial coherente a través de una doble e indisociable politica de repoblación interna y de expansión reconquistadora...", y, por otro, “... el esfuerzo de fijación de fronteras bien delimitadas y estables..." para el territorio bajo su dominio jurisdiccional, como ha señalado C. de Ayala ${ }^{5}$. Tal repoblación tendrá de forma casi invariable un punto de referencia militar o fortificado en un castrum, denominación muy común en las fuentes, que “... identificaba con su nombre al territorio y desempeñaba un papel central en él", como ha señalado P. Martínez Sopena ${ }^{6}$. Tales castra tendrán tamaño y características variables, pero una técnica

\footnotetext{
${ }^{3}$ Rueda, sin embargo, ya se cita en documentos del siglo X (996) como Castro de Rota, en una "Carta otorgada por Velasco Muñiz, Natalia Godo, su mujer y sus hijos, en favor del monasterio de San Salvador, fundado in territorio Balneare locum vocabulo Bobata, y á su abadesa Marina, uernula nostra, en la cual le dan las villas de Bobata, et illu monte Mauroso; ual de Ueneros, Pande, Fonte Veicella, término de Porma, Ilze, y unas viñas in Castro de Rota...". En: Índice de los documentos del Monasterio de Sahagún de la Orden de San Benito, y glosario y diccionario geográfico de voces sacadas de los mismos. Publicados por el Archivo Histórico Nacional. Edición de E. VIGNAU, Madrid, 1874, p. 176, doc. 767 > https://openlibrary.org/books/OL20487473M/ I\%CC\%81ndice_de_los_documentos_del_monasterio_de_Sahagun> [Consultado: 27.01.2016]. Otras denominaciones son: Rota (940), Castro de Rueda (1154), en: A. CALVO (1936-1944). El monasterio de Gradefes: apuntes para su historia y la de algunos otros cenobios y pueblos del Concejo. León, Imprenta provincial, p. 55, y Castro Roda (1181), en: J. RODRÍGUEZ FERNÁNDEZ (1981). Los fueros del Reino de León, 2 vols., León, p. 131.

${ }^{4}$ J. GONZÁLEZ (1944). Alfonso IX, 2 vols., Madrid. CSIC, Instituto Jerónimo Zurita ; J.M. FERNÁNDEZ CATÓN (1991). Colección documental del archivo de la catedral de León, VI (1188-1230), León, doc. 1717, p. 63-65.

${ }^{5}$ C. de AYALA MARTÍNEZ (1996). "Alfonso IX, último monarca del reino de León (1188-1230)". Reyes de León: monarcas leoneses del 850 al 1230 / coord. por C. Álvarez Álvarez, pp. 193-216 (193).

${ }^{6}$ P. MARTÍNEZ SOPENA (1989). "Las pueblas reales de León y la defensa del reino en los siglos XII y XIII”. En LADERO QUESADA, M. Á. [et al.]. Castillos medievales del Reino de León.
} 
edilicia común. En León ciudades como Almanza, Villamartín de Don Sancho, Laguna de Negrillos, y, sobre todo, Rueda del Almirante, conservan testimonios constructivos de estos tiempos, que, en el último caso, como veremos aquí, son realmente notables (Fig. 1). Incluso la propia ciudad de León no fue ajena a estas decisiones, como se puede apreciar en el recinto amurallado y en su propio castillo ${ }^{7}$.

\section{ANTECEDENTES Y ESTUDIOS ANTERIORES SOBRE EL RECINTO AMURALLADO DE RUEDA DEL ALMIRANTE}

La existencia de un castillo con su cerca asociada en la villa de Rueda del Almirante es relatada por la historiografía en diferentes ocasiones. M. GómezMoreno dice de su cerca de cal y canto que, "... yace derribada casi toda, con intento de anular su defensa, probablemente, y sin torres, aunque sobre la enorme cortadura del terreno, a la parte del Esla, divísanse restos de algunas, quizá más modernas $^{8}$. Un militar aficionado a la Historia, J. Mourille López, en el primer tercio del siglo XX, describe sus impresiones sobre Rueda señalando que todavía se podía apreciar, “... sobre la enorme cortadura del terreno, a la parte del Esla, restos de su amurallado recinto de la época de Alfonso $I X^{9}$, algo que, felizmente, se ha conservado después de casi un siglo, si bien no deja de ser curioso que pocos de los que han tratado el sitio más recientemente no hayan reparado en ello. A. Calvo, por su parte, señala que, “... no conserva más que las ruinas de un castillo y de viejas murallas que son como el sello de sus antiguas grandezas...", “... restos y escombros [sobre los que] se levanta un puñado de sencillas casas del país, de la más pobre y humilde construcción"10.

Rueda del Almirante, ya más recientemente, ha sido objeto de atención en el marco de estudios sobre las fortificaciones de la frontera entre Castilla y León, en concreto para subrayar su carácter urbano, por la situación de su castillo-recin-

Fundación Hullera Vasco-Leonesa, pp. 113-137.

${ }^{7}$ J. M. VIDAL ENCINAS, M. L. GONZÁLEZ FERNÁNDEZ, et al (2002). "Un asunto superficial: el revoco decorativo del recinto amurallado romano-medieval de León”. De Arte, 1, pp. 11-20.

${ }^{8}$ M. GÓMEZ MORENO (1925-1926). Catálogo monumental de España. Provincia de León: (1906-1908). Madrid. Ministerio de Instrucción Pública y Bellas Artes, p. 433.

9 J. MOURILLE LÓPEZ (1928). La provincia de León: (guía general), Toledo: Imprenta, Fotograbado y Encuadernación del Colegio de María Cristina.

${ }^{10}$ A. CALVO, (1936-1944). El monasterio de Gradefes: apuntes para su historia y la de algunos otros cenobios y pueblos del Concejo. León, Imprenta provincial, p. 55. 
to en la parte más elevada y periférica, todo ello construido de 'cal y canto', como otras fortificaciones similares del ámbito castellano y leonés ${ }^{11}$.

La Carta Arqueológica de la provincia de León, en su primera edición de 1987-1988 12 , incluyó tanto el castillo como el recinto amurallado en su catálogo, pero de forma muy somera, sin proporcionar plano o croquis de ninguno de los dos, algo que prácticamente se repite en la revisión que de la misma tuvo lugar en $1996^{13}$, si bien aquí se proporcionan detalles de las dimensiones y forma del primero de ellos. Se dice, en concreto, que se trata de, “... una estructura de planta rectangular cuyo eje mayor, orientado norte-sur es aproximadamente de $37 \mathrm{~m}$, mientras que el este-oeste mide $32 \mathrm{~m}$ ", que corrigen las dimensiones aportadas por primera vez de esta construcción por Mañanes, Valbuena y Alonso Ponga en 1980, a saber, $30 \mathrm{~m}$. de lado E-O y $28 \mathrm{~m}$. de lado N-S ${ }^{14}$.

En tiempos casi coetáneos, en el marco de una investigación académica, Gutiérrez González enjuició el estado del conjunto considerando que de la “... primitiva fortificación castreña apenas subsisten restos (...)", aunque se apunta la existencia de "... vallados terreros en las laderas...", pero de los que no se aporta mayor precisión. Del recinto de murallas de cal y canto, que sustituirían a aquella, este mismo autor dice que tiene una 'planta trapezoidal ligeramente irregular', del que "Se aprecian restos de una puerta muy derruida junto al ángulo sureste...", así como "... retazos sueltos [de las cercas] al noreste, sureste y suroeste, sobre los que se asientan las casas de la localidad". Además, tendría otra puerta el castillo al norte, de todo lo cual no se aporta plano o croquis de situación. Lo que no es obstáculo, sin embargo, para conceder al recinto una superficie de algo menos de una hectárea $(0,84)$ y del que no se realiza propuesta de reconstrucción de su circuito, si bien se proporcionan unas dimensiones para el mismo de 130 x 90/40 m. Sin embargo, como queda de manifiesto en la cartografía que aportamos (Fig. 4), el eje mayor del recinto, una línea Norte-Sur que arranca de una de las esquinas del castillo, la más septentrional, hasta las inmediaciones de un cubo o torre macizos que se encuentra en la traza de la cerca,

\footnotetext{
${ }^{11}$ J. L. ALONSO PONGA, F. VALBUENA y T. MAÑANES PÉREZ. (1980a). "La arquitectura militar en la frontera del Reino de León con el de Castilla, en los siglos XII y XIII” (I), Tierras de León, Vol. 20, No 40, pp. 89-114 (111), idem. 1980b. "La arquitectura militar en la frontera del Reino de León con el de Castilla, en los siglos XII y XIII (II)”. Tierras de León, Vol. 20, № 41, pp. 59-88 (85-86).

${ }^{12}$ Este primer documento de registro del Patrimonio Arqueológico de la provincia de León fue promovido por la Diputación Provincial de León, bajo la coordinación de J. L. AVELLO ÁLVAREZ.

${ }^{13}$ Las tareas fueron contratadas por la Junta de Castilla y León (Dirección General de Patrimonio Cultural) a un equipo formado por los arqueólogos A. BALADO PACHÓN y L. C. SAN MIGUEL MATÉ.

${ }^{14}$ O.c., 1980a, p. 111.
} 
alcanza $285 \mathrm{~m}$ de longitud. El mismo investigador, además de recoger que la muralla se construyó por medio de encofrados de cal y canto de $0,9 \mathrm{~m}$ de altura, señala que su anchura es de 2,6/2,8 $\mathrm{m}$ y de 1,4 para el castillo, cifras que creemos están intercambiadas por error, puesto que son claramente más anchos los muros del castillo que los de la cerca ${ }^{15}$.

En el año 2000 una importante síntesis sobre el origen y urbanismo de las ciudades medievales en Castilla y León no incluye Rueda del Almirante entre el importante repertorio establecido ${ }^{16}$.

Ya en estos últimos años, diferentes estudios promovidos y financiados por la Junta de Castilla y León, dentro de las pautas y metodología del Plan PAHIS 2004-2012 del Patrimonio Histórico de Castilla y León, han tratado de manera desigual sobre el castillo y recinto amurallado de Rueda del Almirante. El primero de ellos, de 2011 - un catálogo de arquitectura fortificada de Castilla y León -, no aporta nada nuevo para el conocimiento de las características que tiene su implantación topográfica y restos conservados ${ }^{17}$. Este estudio, cuyo catálogo de la provincia de León fue elaborado por el arqueólogo M. Retuerce, creemos, además, que contiene errores, entre otros, decir que se encuentran 'sin restos' los castillos de Aguilar (Sabero), Santa Colomba de Curueño, Los Barrios de Gordón, Portela de Aguilar, Siero de la Reina, el castillo de Luna (Los Barrios de Luna), el de Mena de Babia ${ }^{18}$, en Cabrillanes, o la llamada 'Mota Alta' de Valmartino, cuando de alguno de ellos existen plantas publicadas en la bibliografía que se cita en la obra, y que su realidad material hoy - ninguno ha sido objeto de

\footnotetext{
${ }^{15}$ GUTIERREZ GONZALEZ, o.c., p. 281 y Cuadros 1.4 y 1.5 en p. 44 y 56, dedicado a 'Recintos amurallados de ciudades y villas'. Aunque el autor se refiere explícitamente al recinto al proporcionar dicha superficie es probable que se trate de un error y que, en realidad, se esté refiriendo al castillo, cuya área, en efecto, es similar a la cifra proporcionada.
}

${ }^{16}$ F. BENITO MARTÍN (2000). La formación de la Ciudad Medieval. Universidad de Valladolid. Secretariado de Publicaciones.

17 F. COBOS GUERRA, y M. RETUERCE VELASCO (2011). Metodología, valoración y criterios de intervención en la Arquitectura fortificada de Castilla y León. Catálogo de las provincias de León, Salamanca, Valladolid y Zamora. Junta de Castilla y León. Consejería de Cultura y Turismo. Publicación Electrónica: http://www.patrimoniocultural.jcyl.es/web/jcyl/ PatrimonioCultural/es/Plantilla100DetalleFeed/1284180255460/Publicacion/1284222646284/ Redaccion [consultado:23.12.2015]

${ }^{18}$ Se nombra a la localidad como "Mena de los Cilleros" cuando, en realidad, es Mena de Babia. Aquí, en un imponente roquedo - la Peña del Castillo -, desde el que se domina buena parte del espléndido valle babiano, se encuentran los restos de una de las fortificaciones medievales más enriscadas entre las que conocemos de la provincia de León; no en vano se encuentran a $1.488 \mathrm{~m}$ de altitud. Por el lado más accesible, a $1.245 \mathrm{~m}$ de altitud, hay que subir, a lo largo de unos $600 \mathrm{~m}$, para salvar un desnivel de unos $230 \mathrm{~m}$, luego casi el $40 \%$. Los restos, de mampostería tomada con argamasa, son, por lo demás, imponentes. 
excavaciones arqueológicas, ni antes ni después de la publicación que tratamos -, se confirma plenamente sobre el terreno, lo que quiere decir que sus restos son bien evidentes ${ }^{19}$.

En 2012, otro de estos estudios presenta, por primera vez, un plano de la implantación del recinto y castillo de Rueda del Almirante, aunque sin referencia topográfica alguna y, como justificación de la propuesta, parece aducirse el, “... tenor del entramado urbano y de los escasos restos localizados", algo, esto último, en lo que se enfatiza, puesto que, “... del recinto de la puebla solo quedan pequeños tramos insertados en las construcciones existentes"; o bien que posee "... escasos restos localizados". Además, se indica una nueva superficie para el conjunto, 1,7 Ha, que dobla la propuesta por Gutiérrez González en el trabajo citado más arriba, en función del perímetro del recinto que se propone ${ }^{20}$.

Cobos Guerra, de Castro Fernández y Canal Arribas proporcionan observaciones técnicas sobre el sistema de construcción del encofrado, que sería 'de agujas recuperables', con la particularidad de que los mechinales se habrían realizado con tejas curvas cerámicas para insertar en ellos unas agujas de madera, seguramente cilíndricas, que podrían así extraerse fácilmente. Estos autores dan una anchura para los muros del castillo de 2,5 y para la cerca de 2,4 m, así como una altura para las tapias del encofrado de 1,2 m, con una longitud de 2,6 m.

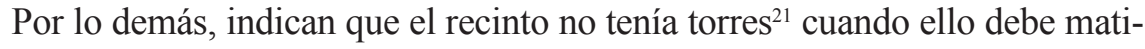
zarse, puesto que en la ladera que mira al río Esla, existe una torre o cubo macizo aún conservado en el trazado de la cerca, perfectamente visible, ya sea desde la carretera que corre al pie del cerro, ya sea desde el mirador existente en el paseo que rodea a la villa en su punto más meridional, uno de los que proporciona las mejores vistas del valle del Esla. Buena parte de los observadores de los restos de Rueda que mencionamos en la historiografía (vid. supra) se dieron cuenta de su existencia.

\footnotetext{
${ }^{19}$ COBOS GUERRA y RETUERCE VELASCO, o.c., p. 12 y $\S 4$ en p. 181, "Elementos no verificados como fortificaciones medievales o modernas". Las plantas del castillo de Aguilar en Sabero, Santa Colomba, Los Barrios de Gordón, Valmartino y Siero de la Reina en la obra ya citada de GUTIÉRREZ GONZÁLEZ, pp. 284, 292, 194, 317 y 296, respectivamente. Del castillo de Gordón ya había publicado una planta J.M. LUENGO en 1928: Monumentos Militares Leoneses. I. -El Castillo de Gordón. II-Las Cercas de Valderas. León. Imprenta y Librería de Jesús López, p. 22, Fig $1^{\mathrm{a}}$.

${ }^{20}$ F. COBOS GUERRA, J.J. de CASTRO FERNÁNDEZ, y R. CANAL ARRIBAS (2012), Castros y recintos en la frontera de León en los siglos XII y XIII. Fortificaciones de tapial de cal y canto o mampostería encofrada. Junta de Castilla y León. Consejería de Cultura y Turismo. < http:// www.patrimoniocultural.jcyl.es/web/jcyl/PatrimonioCultural/es/Plantilla100Detalle/128421 7324650/_1284228008981/Redaccion > [consultado: 23.12.2015], en la p. 144, 'Tabla comparativa de castros estudiados', se aporta el plano al que nos referimos $\left(n^{\circ} 13\right)$.
}

${ }^{21}$ Castros y recintos, cuadro en p. 278. 
Estas pequeñas torres o cubos macizos que, a modo de contrafuertes, jalonaban la cerca para darle consistencia o rigidez, especialmente en las esquinas, las conocemos también gracias a un precioso documento: un plano de Rueda del Almirante datado hacia 1600-1630, dibujado desde el sureste, desde el valle del Esla, que muestra, además de los restos aun bien visibles de la muralla, cinco de estas torrecillas o cubos macizos que poseía en este lienzo, de los que hoy únicamente resta el más occidental, que se denomina 'Peña del Cubo', al que aludimos más arriba. El plano fue dado a conocer por L. A. Grau Lobo en 1996 y V. Jimeno, de quienes lo tomamos, es quien ha propuesto la cronología que recogemos para este documento, con los detalles de su azaroso hallazgo ${ }^{22}$ (Fig. 3).

Finalmente, otro de estos estudios recientes, coetáneo del anterior - los tres prácticamente lo son -, puesto que fue también realizado en 2012, en el que participaron arquitectos, historiadores, arqueólogos e historiadores de Arte, describe desde el punto de vista histórico y tipológico 27 fortificaciones de frontera entre las que se encuentra Rueda del Almirante, de la que se dice que "... quedan pocos restos" 23 . Aquí incluyen un plano idéntico al de la publicación anterior, pero con la diferencia de que se va a superponer a un fotograma aéreo tomado del SIGPAC, que incluye también al castillo (Fig. 2), de tal manera que se obtiene una referencia de la situación topográfica, tanto de la cerca como de aquel. La superficie que encerraría tal recinto, incluyendo el castillo, sería la del estudio precedente unas 1,7 Ha, con un perímetro que tendría una longitud de aproximadamente $525 \mathrm{~m}$. Hasta donde llega nuestro conocimiento, se trataría del primer y único intento de representación topográfica, publicado, del conjunto fortificado de Rueda ${ }^{24}$. Sin embargo, como veremos a continuación, este plano está lejos de representarlo de forma acertada, pues salvo el recinto del castillo y un pequeño tramo de la cerca - unos $75 \mathrm{~m}$-, que acomete a su esquina más oriental, en todo lo demás está descaminado.

${ }^{22}$ L. GRAU LOBO (1996). "Eruditos, pioneros e historiadores de la arqueología leonesa», en ArqueoLeón. Historia de León a través de la arqueología, Junta de Castilla y León-Diputación Provincial de León, pp. 226; V. JIMENO (2011). "De pleitos, comisiones y eruditos: la historia de la «Cueva del Cubo» de Rueda del Almirante (León)”. De Arte, 10, 2011, pp. 7-20.

${ }^{23}$ A. GONZÁLEZ DÍAZ (coord.), A. BALADO PACHÓN, et al. (2012). Fortificaciones de los siglos XII y XIII en las fronteras del reino de León. Junta de Castilla y León. Consejería de Cultura y Turismo. < http://www.patrimoniocultural.jcyl.es/web/jcyl/PatrimonioCultural/es/Plantilla 100Detalle/1284217324650/_/1284223351377/Redaccion > [consultado: 23.12.2015], p. 45.

${ }^{24}$ Existe, sin embargo, un croquis muy atinado del castillo y recinto amurallado en un folleto manuscrito por su autor, E. URDIALES LAREDO, fechado en 2001 - el plano en 1995 -, que lleva por título: Historia de la villa y tierra de Rueda del Almirante: episodios concejiles de la Comarca de Rueda, D.L. 2001, documento que está disponible dentro del Catálogo de la Biblioteca Pública de León. El plano que acompaña es una interpretación totalmente correcta de la implantación del recinto, por lo que, aun tratándose de una edición peculiar, debe anotarse en puridad a su autor como auténtico precursor. 


\section{LA REAL IMPLANTACIÓN DEL RECINTO AMURALLADO DE RUEDA DEL ALMIRANTE}

La información actualmente existente sobre la arquitectura fortificada de esta villa, especialmente aquella que tiene implicaciones de tipo normativo para la conservación de un bien que únicamente tiene la inconcreta protección que se deriva del decreto de 1949 de la Dictadura franquista, que protege genéricamente a los castillos españoles es muy pobre ${ }^{25}$. Con la finalidad de revisar la información existente en la Carta Arqueológica sobre este sitio y el propósito de que su correcta identificación sirva como instrumento para la mejor conservación de sus restos, hemos realizado varias visitas a la villa para, sobre el terreno, registrar todas las evidencias materiales que depara su conjunto fortificado.

Nuestro trabajo se ha basado en la observación directa y registro georreferenciado de los datos obtenidos sobre el terreno, lo que nos ha permitido reconstruir de manera creemos que fidedigna la realidad del mismo, la cual está muy alejada de todas las opiniones que, hasta el momento, se han vertido sobre este recinto (Fig. 4). La verdadera realidad material de sus restos es que son mucho más evidentes que los que de forma premiosa se han descrito. Pero es que, además, es mucho más grande que lo que se había señalado, pues albergó una superficie de $2,8 \mathrm{Ha}$ en un circuito amurallado cuyo perímetro es de casi $750 \mathrm{~m}$ (749.1), e, incluyendo los muros del castillo, supera los $800 \mathrm{~m}$ de longitud ( 805.8 $\mathrm{m})$. De ellos, además, son apreciables sobre el terreno sus trazas en más de $500 \mathrm{~m}$ (509) conservados, es decir, el $63 \%$, incluyendo la mayor parte de los restos del castillo, al que solo le falta su lado suroccidental, que, no obstante, como seguramente todo lo faltante a la observación directa, estará conservado en el subsuelo. Esta fortaleza ocupa la parte más elevada del recinto, pues se encuentra a $905 \mathrm{~m}$ de altitud, situándose la parte más baja de éste, al sur, en torno a la cota de $875 \mathrm{~m}$.

Así, por ejemplo, el lienzo de más de $300 \mathrm{~m}$ de longitud que cerraba el recinto por el sureste, apuntado en el plano histórico de la Fig. 3., ha quedado perfectamente corroborado sobre el terreno. Este tramo de la cerca se avanzó a media ladera - fuera de la parte superior de la plataforma que estaría ocupada -, por razones poliorcéticas, las de controlar visualmente la base o pie del cerro al nivel del valle del río. Este tramo, aunque se encuentra muy arrasado, sería fácilmente recuperable arqueológicamente en el futuro. Constituiría, creemos, un gran elemento del Patrimonio Histórico de esta Villa, si alguna vez se llega a su investigación, restauración y presentación al público.

${ }^{25}$ Decreto de 22 de abril de 1949 sobre protección de los castillos españoles. BOE núm. 125, de 5 de mayo de 1949. 
El perímetro del castillo debió tener unos $120 \mathrm{~m}$ de longitud y encerraría una superficie que no alcanzaba la hectárea $(0,089)$, si bien pudo ser mayor, pues su lado que mira a suroeste no presenta en la actualidad restos visibles. Tal hipótesis sobre su superficie coincide con la avanzada por otros autores ${ }^{26}$.

Otro rasgo que aquí queremos poner en evidencia es que el recinto amurallado de Rueda estuvo provisto de un foso que lo rodeaba en buena parte de su perímetro, en concreto, en sus lados septentrional, oriental y occidental, los de más fácil acceso, y no fue necesario construirlo para el importante tramo que se encuentra fuera del actual caserío, debido a que, por la acusada pendiente en la que se trazó, era innecesario. Su anchura está comprendida entre los 25-30 m y, especialmente el occidental, ocupado en la actualidad por caserío urbano.

${ }^{26}$ F. COBOS GUERRA, J.J. de CASTRO FERNÁNDEZ, y R. CANAL ARRIBAS, o.c. en Nota 20, p. 279 , dan la cifra de $0,097 \mathrm{Ha}$. 
Fig. 1. Situación de Rueda del Almirante y otras ciudades en la frontera Cea-Esla entre los reinos de Castilla y León

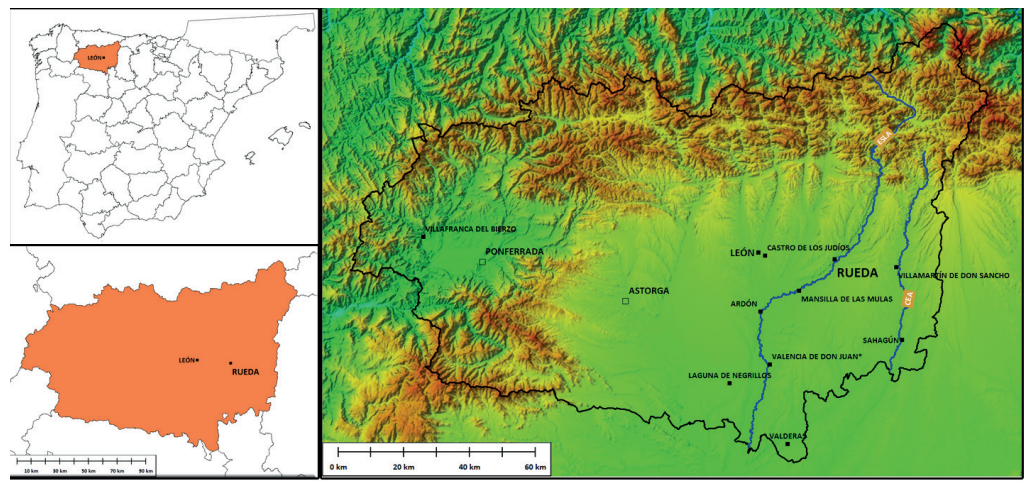

Fig. 2. El castillo y recinto amurallado de Rueda del Almirante según A. GONZÁLEZ DÍAZ (coord.), A. BALADO, et al. (2012) (imagen grande) y según COBOS GUERRA et al. (2012) (imagen pequeña). Ambos planos, prácticamente idénticos, no reflejan la realidad del recinto, salvo en lo que se refiere al del castillo - en la parte superior de ambas imágenes -, y un tramo de 75 m de la cerca que acomete a su esquina más oriental. El tramo en rojo - o en negro en la imagen pequeña -, que correspondería a los únicos restos conservados según dichos autores, lo sitúan mal, pues no se encuentra en esa calle, sino en la paralela por el este. El cierre meridional lo justifican por el entramado urbano, pero es inexistente (cf. Fig. 4 en este artículo)

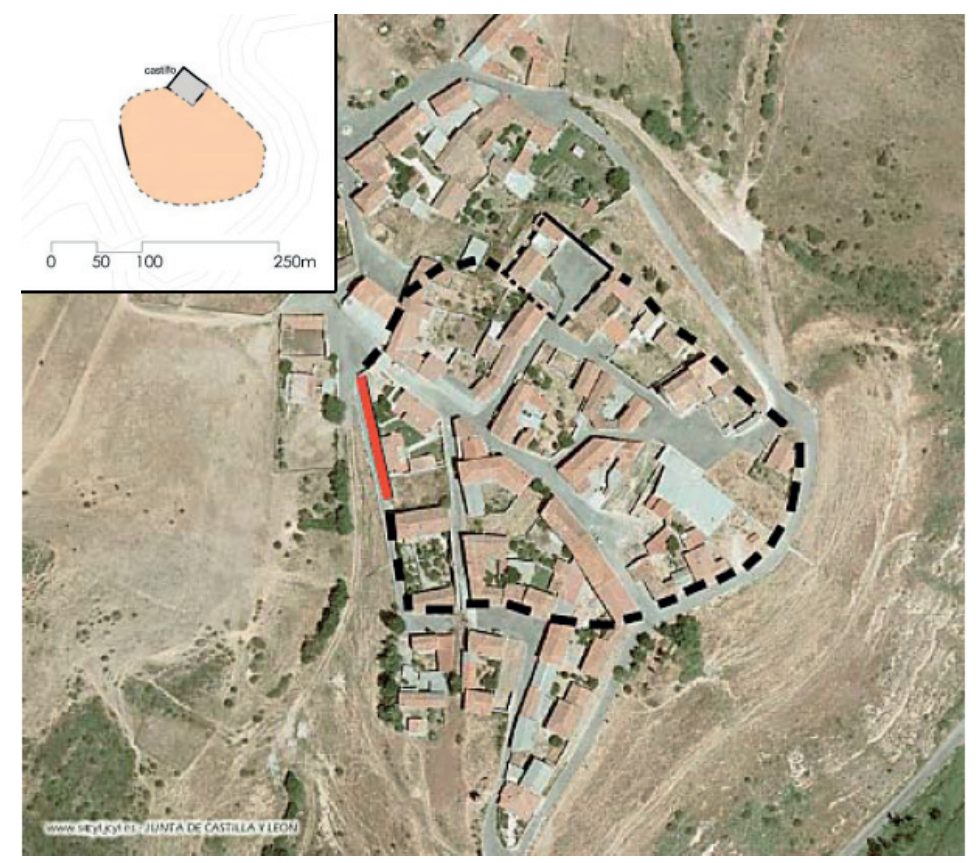


Fig. 3. Plano de Rueda del Almirante desde el sureste, c. 1600-1630. Este plano muestra, por encima de la leyenda 'Castro de Rueda', situada en el centro, la línea de la muralla y, numeradas del 1 al 5, las cinco torrecillas o 'cubos' macizos que poseía, de los que únicamente resta el más occidental, denominado 'Peña del Cubo'(Fuente: GRAU LOBO, 1996 y JIMENO, 2011).

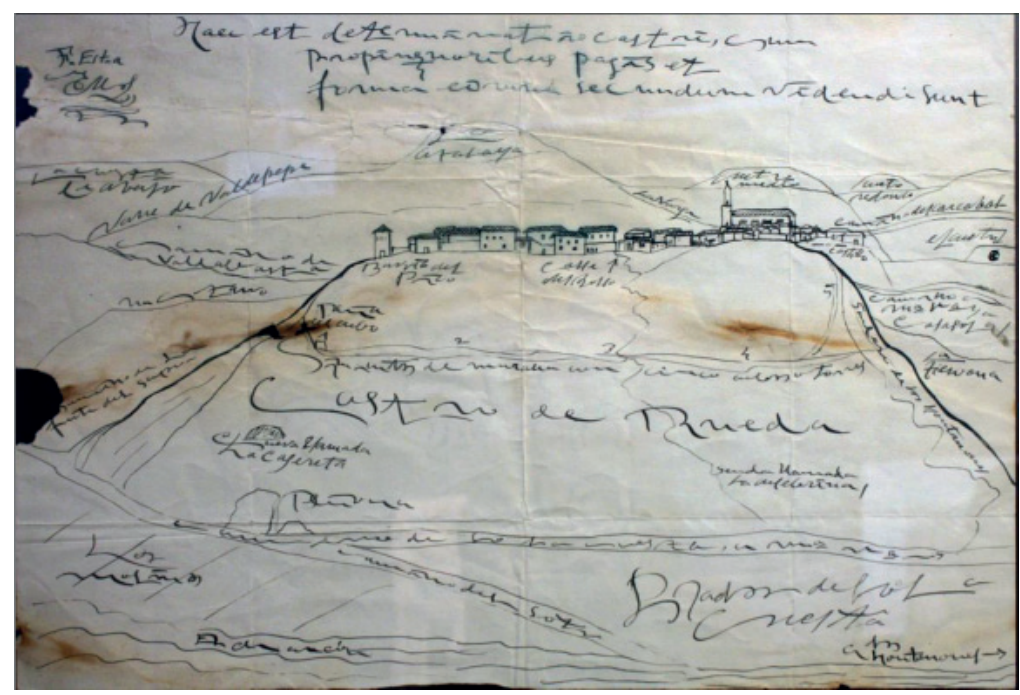

Fig. 4. El castillo y recinto amurallado de Rueda del Almirante, según los restos conservados (línea continua en color rojo). La imagen MDT de la izquierda permite reconocer la presencia de fosos en el recinto y el lienzo oriental situado a media ladera, todo ello trasladado al caserío actual (LIDAR-PNOA cedido por el Instituto Geográfico Nacional)

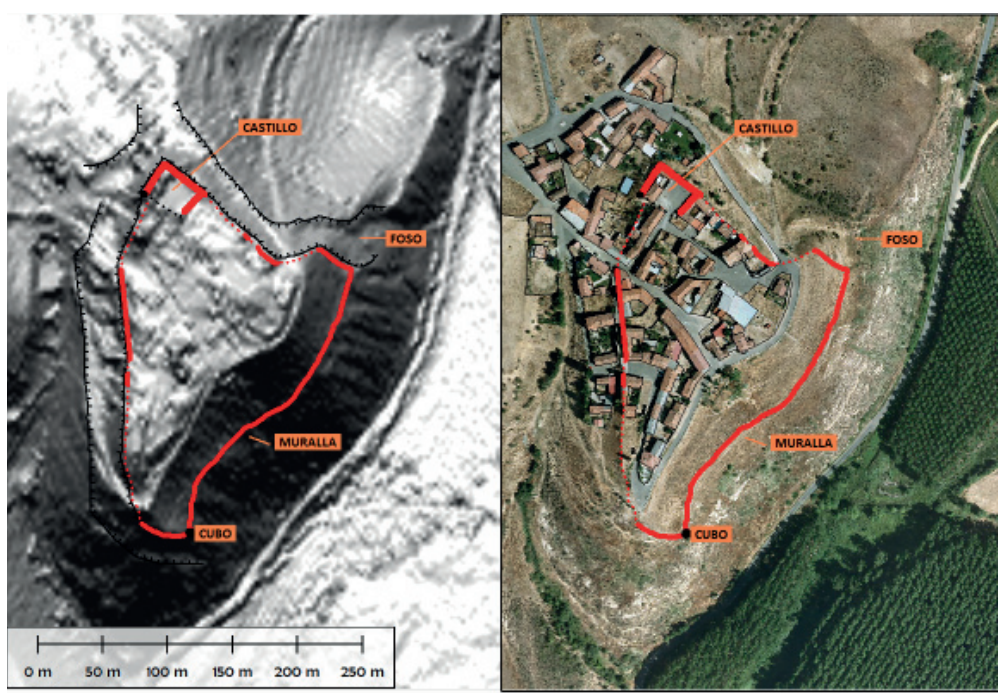

